\title{
Research on Cognitive Effects of Narrative Rhetoric in Print Advertisement Based on Eye Movement
}

\author{
Yubo Li ${ }^{1, a^{*}}$, Gong Wang ${ }^{2, b}$, Quan Gan ${ }^{3, c}$ \\ ${ }^{1}$ Department of visual communication, Art School of Jiangsu University Zhenjiang, Jiangsu, China \\ ${ }^{2}$ Department of Digital Media and Animation, Art School of Jiangsu University Zhenjiang, Jiangsu, China \\ ${ }^{3}$ Department of Digital Media and Animation, Art School of Jiangsu University Zhenjiang, Jiangsu, China
}

\begin{abstract}
This article uses eye movement experiments to study the cognitive effects of consumer groups on different narrative-quality advertisements. The experiment selects typical advertising cases, takes college students as subjects, and uses computers to track and analyze eye movement data. The experimental results show that the quality of narrative rhetoric directly affects the number of attention, duration, and pupil diameter of the subjects, and the subjects' browsing time and memory of advertisements are positively related to the quality of narrative rhetoric of advertisements. Among them, in the Low-involvement/Thinking product advertisements, consumers' eye movement data for advertisements with better narrative quality is relatively more significant.
\end{abstract}

\section{INTRODUCTION}

Since the moment of its birth, advertisements naturally possess the purpose of persuasion. Therefore, advertisements are regarded as a typical rhetorical research corpus. The influence of advertisement text and images on audiences' thinking and behavior can be studied through rhetorical theory. As a unique rhetorical device, the narration is often used in advertisements. In print ads, narratives exist in the form of images. Eye-tracking data is an important basis for evaluating the impact of images on the audience. Therefore, in theory, the physiological indicators of eye movement experiments can be used to evaluate the cognitive effects of image narration on the audience.

\section{RELATED RESEARCH}

\subsection{Related research on narrative rhetoric in advertising design}

When someone tells a specific story for a specific audience for a specific purpose in a specific situation, a narrative occurs. From the very beginning, the narration is a persuasive method aimed at influencing the audience, so the narration is rhetoric[1]. Narrative as a rhetorical means is not uncommon in advertising. Narrative advertising focuses on creating stories around brands and satisfying consumers' emotional needs. Its purpose is to attract consumers' attention to products and encourage them to buy products[2]. Consumers see advertisements and produce narrative advertising judgment behaviors, map their own life experience and emotions from the

\footnotetext{
ae-mail: 442000875@qq.com

be-mail: 16832531@qq.com

ce-mail: 82656140@qq.com
}

advertising storyline, and have an understanding of the protagonist's emotions in the advertising plot, which can improve the evaluation of the advertisement, thereby enhancing the advertising Product and service recognition[3], Some researchers believe that the narrative paradigm theory should be used as the basis for evaluating the audience value conflict of advertising images[4].

\subsection{Application of eye movement in the evaluation of advertising design effect}

When the audience interprets an image, the physiological indicators of eye movement are the digital representation of consumers' psychological responses to the image, and eye movement technology is a scientific and effective tool for measuring the psychological responses of the image. Scholars have achieved empirical evaluation of the relationship between advertising images and effects through eye movement experiments. These evaluations are mainly divided into three types: the first is the evaluation of the advertising effect caused by the arrangement of advertising images, such as layout[5], image area [6], location[7], and background complexity[8]. The second is to evaluate the effectiveness of advertising content appealing forms [9] such as graphics or text[10]; the third is to evaluate the effectiveness of visual rhetorical means such as image metaphors[11].

Based on the above research, this article proposes the following two research goals through eye movement experiments: on the one hand, to test whether different narrative rhetorical quality advertisements have corresponding cognitive effects through physiological 
indicators of eye movement; on the other hand, narrative rhetorical advertisements target different levels of involvement Whether there is a difference in the cognitive effect of the product. The research results will have an important reference role for the advertising and marketing practices of enterprises.

\section{EXPERIMENTAL OBJECTS AND METHODS}

\subsection{Subject}

Select 30 undergraduates, including 15 males, 15 females, 16 science and engineering majors ( 8 male and female), 14 humanities majors ( 7 male and female), to balance the gender and knowledge literacy of the experimental subjects. The subjects' naked vision or corrected vision was above 1.0.

\subsection{Experimental materials}

\subsubsection{Determination of product type}

In terms of product type selection, this study refers to the FCB grid system for product type classification, combined with the consideration of the consumption level of college students, this study finally selected two product types: high-quality headphones (first quadrant: High Involvement/Feeling), anti-acne products (third quadrant: Low Involvement/Thinking). These two products have a high degree of attention among college students and are typical in the opposite FCB grid. The stimulus advertising works are selected from these two product advertisements.

\subsubsection{Source of advertising works}

The advertising materials for this study were obtained from professional advertising websites, and two groups of advertisements that meet the research objectives were collected, and two academics taught by college advertising design courses and one advertising business expert with more than 10 years of industry experience are based on this research. The narrative rhetoric quality of the advertisements was divided and 6 print advertisements were finally selected.

\subsubsection{Treatment of advertising works}

First of all, the original brand of the 6 print advertisements in this study are inconsistent, but the advertising requirements are the same, so the brand logo is unified, the headset brand is unified to "JBL", the slogan is unified to "isolate noise", and the acne removal products are unified to "Teatree" and the slogan are unified as "end acne trouble". This treatment first eliminates the influence of brand preference, and secondly avoids the difference in the rhetorical effect of the slogan outside of narration. Previous studies have shown that different positions of information have a significant impact on eye-tracking data and advertising effects[7]. Therefore, before this research experiment, Adobe Photoshop software was used to unify the brand logo and slogan of the advertisement: they are placed in the lower right corner of the screen, size It is $1 / 48$ of the screen, to ensure that the subject's eye movement differences and advertising memory are not caused by the position of the brand in the advertising screen.

The final experimental materials and classification are as follows:
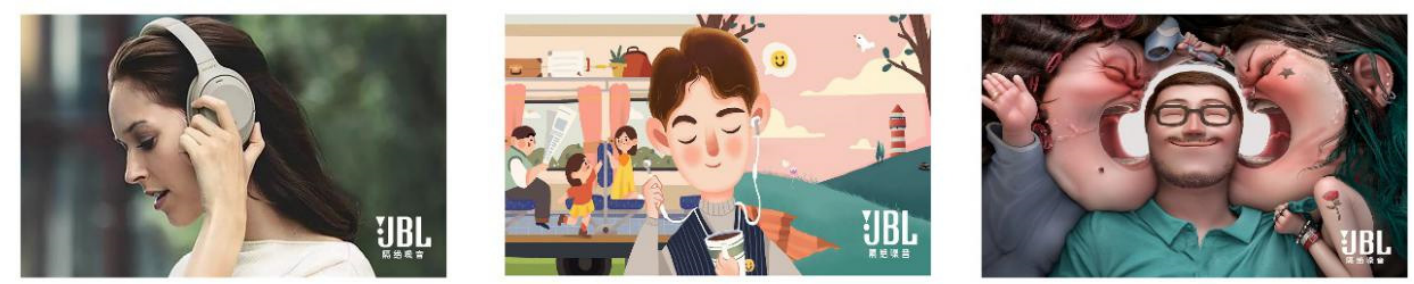

Figure 1 Noise-cancelling headphones-no narrative ads $\backslash$ low narrative quality ads $\backslash$ high narrative quality ads
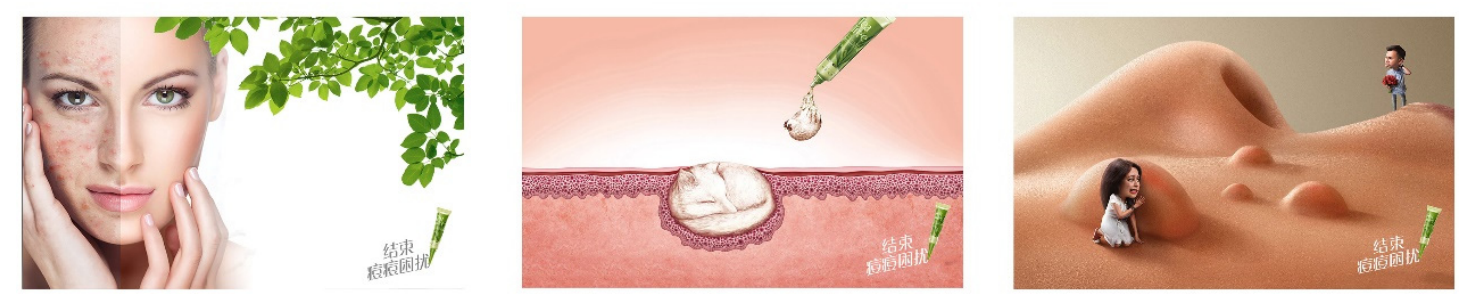

Figure 2 Anti-acne products-non-narrative ads \low narrative quality ads \high narrative quality ads

\subsection{Experimental variables}

\subsubsection{Independent variables}

Independent variable 1: No narrative rhetorical advertisement: The images in the advertisement do not use any narrative skills, and only use pictures to directly describe the appearance or the effect of the product. Low narrative rhetorical quality advertisements: The images in the advertisements use narrative techniques to present product effects, showing a certain dramatic conflict. High-quality narrative rhetorical advertisements: The images in the advertisements use narrative techniques to 
present product effects, and use strong dramatic conflicts to show the product functions and effects that users care about.

Independent variable 2: high-involvement products (high-quality noise reduction headphones) and low-involvement products (acne removal products).

\subsubsection{Dependent variable}

The gaze time, the number of gazes, and pupil diameter of the eyes during the operation of the subject.

\subsection{Experiment equipment}

This experiment uses the Tobii T60XL eye tracker in the school laboratory, which can record the user's gaze length, the number of times, pupil diameter, and eye movement characteristics when processing visual information.

TABLE 1 Comparison Of The Average Attention Time Of Advertisements With Different Narrative Rhetoric Qualities (Standard Deviation In Parentheses)

\begin{tabular}{ccccccc}
\hline \multicolumn{1}{c}{ Product type } & \multicolumn{2}{c}{ High Involvement/Feeling } & \multicolumn{2}{c}{ Low Involvement/Thinking } \\
\hline Rhetorical quality & No narrative & $\begin{array}{c}\text { Low } \\
\text { narrative } \\
\text { quality }\end{array}$ & $\begin{array}{c}\text { High } \\
\text { narrative } \\
\text { quality }\end{array}$ & $\begin{array}{c}\text { No } \\
\text { narrative }\end{array}$ & $\begin{array}{c}\text { Low } \\
\text { narrative } \\
\text { quality }\end{array}$ & $\begin{array}{c}\text { High } \\
\text { narrative } \\
\text { quality }\end{array}$ \\
$\begin{array}{c}\text { Average fixation time (s) } \\
\begin{array}{c}\text { The Average number of } \\
\text { fixations (times) }\end{array}\end{array}$ & $5.04(1.12)$ & $12.32(1.05)$ & $25.27(1.13)$ & $5.27(0.98)$ & $11.23(1.05)$ & $19.27(1.09)$ \\
\hline
\end{tabular}

The subject's gaze time and the number of gazes on the test content reflect the degree of attention to the gaze content. Judging from the above indicators, the narrative rhetoric advertisements introduce stories, and the subjects pay more attention to the content of the advertisements and can watch the advertisements with great interest. This depends on the entertainment effect of the narrative. In the case of anti-acne product advertisements, low-quality narrative advertisements use event analogy to rationally

\subsection{Experimental procedure}

The experiment conducts a single test for each subject. The specific steps are: (1) Calibrate the equipment and pre-experiment with exercise materials. (2) Start the experiment. The longest viewing time for each picture is 60 s. The test subjects can switch to the next picture by themselves within 60s. The switched picture is automatically placed on the gray screen for $3 \mathrm{~s}$ and then the next picture is displayed. (3) After viewing all 6 pictures, leave the experimental location.

\section{EXPERIMENTAL RESULTS AND ANALYSIS}

\section{1 fixation time and frequency}

persuade the acne removal function, while high-quality narrative advertisements directly start from the user's pain point-the embarrassment of acne in life. Perceptual persuasion, focusing on user emotions from an indicator perspective can trigger emotional responses more than product function explanations.

\subsection{Pupil diameter}

TABLE 2 Comparison Of Pupil Diameters Of Advertisements With Different Narrative Rhetorical Qualities (Standard Deviation In Parentheses)

\begin{tabular}{ccccccc}
\hline Product type & \multicolumn{3}{c}{ High Involvement/Feeling } & Low Involvement/Thinking \\
\hline Rhetorical quality & No narrative & $\begin{array}{c}\text { Low narrative } \\
\text { quality }\end{array}$ & $\begin{array}{c}\text { High } \\
\text { narrative } \\
\text { quality }\end{array}$ & $\begin{array}{c}\text { No } \\
\text { narrative }\end{array}$ & $\begin{array}{c}\text { Low narrative } \\
\text { quality }\end{array}$ & $\begin{array}{c}\text { High } \\
\text { narrative } \\
\text { quality }\end{array}$ \\
$\begin{array}{c}\text { Pupil diameter } \\
(\mathrm{mm})\end{array}$ & $3.746(1.12)$ & 4.157(1.05) & $5.756(1.13)$ & $\begin{array}{c}3.334(0.9 \\
8)\end{array}$ & 4.521 (0.43) & 5.206 (0.17)
\end{tabular}

The pupil diameter of the subject is also an important indicator of interest in the gaze content. Judging from the above indicators, photo-real images have more advantages in expressing character emotions than illustrations. In the case of headset advertising, both low-quality and high-quality narrative advertisements introduce changes in character emotions, but in high-quality rhetorical advertisements, characters' emotional expression is stronger, and the picture is more realistic, so the above indicators are better. It can be seen that in the image narrative, the picture of photo-realism is more substituting than the performance of illustrations. 


\subsection{Average fixation time and fixation rate of interest area}

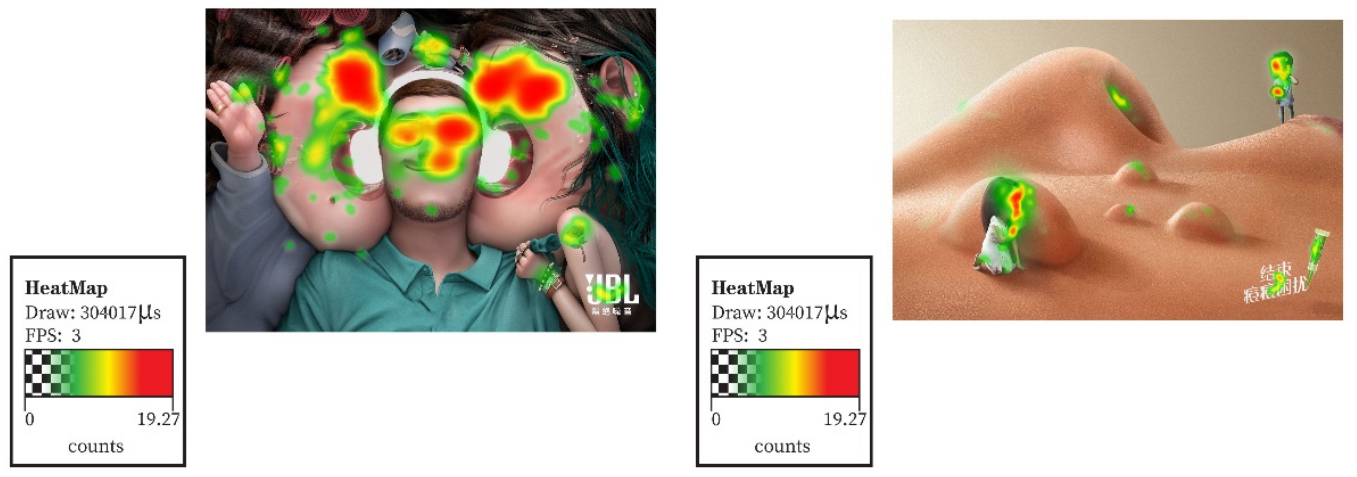

Figure 3 Viewer heatmap of two high-quality rhetorical advertisements

Judging from the hot spots of two high-quality narrative rhetorical advertisements (Figure 3), the subjects' attention is focused on the expressions and actions of the characters in the two advertisements, which also confirms the advertisement images in the relevant research [5], the main effect of the characters on the area of interest and the guiding effect of the characters' eyes on the viewer. The intense dramatic conflict in the advertisement images brought emotional agitation effects to the subjects, which resulted in an emotional identification with the protagonist's story in the narrative rhetoric, and thus increased the popularity of the advertisement's products and services.

\section{CONCLUSION}

This research explores the effects of different narrative rhetoric qualities on eye movement behavior in print advertisements for different consumer products. The research found that the higher the narrative rhetoric quality in advertising works, the higher the fixation points and the fixation time, the easier it is to trigger emotional reactions, and there is a consistent response in different types of consumer product advertisements. The advertising images with high narrative rhetoric quality have a significant main effect on the gaze points and gaze time of the viewers watching the work. The gaze points and gaze time of the viewers are important indicators to judge whether the viewer is interested in the advertisement. Therefore, it can be inferred that adding narrative content and drama conflict in the advertising design is more likely to attract the attention of the audience, thereby enhancing the viewer's willingness to choose brands and products.

\section{ACKNOWLEDGEMENT}

This research work of this paper is supported by the 2019 University Philosophical and Social Sciences Research Program titled "Research on the Design Strategy of Tourism Cultural and Creative Products from the Perspective of Rhetoric" (No.: 2019SJA1874).

\section{REFERENCES}

1. Phelan, James, Narrative As Rhetoric: Technique, Audiences, Ethics, Ideology[M]. Columbus, Oh: Ohio State University Press, 1996

2. Recep Yilmaz, Narrative Advertising Models And Conceptualization In The Digital Age[M]. Igi Global, 2017

3. Zhang yang. Study on the emotional resonance effect of narrative advertising[J]. Journalism and mass communication monthly, 2014(19): 9-16.

4. Nancy b. Stutts, Randolph T. Barker, The Use Of Narrative Paradigm Theory In Assessing Audience Value Conflict In Image Advertising[J]. Management Communication Quarterly, vol. 13, no. 2, November 1999 209-244.

5. Bai xuejun, Zhang Yu, Yao Haijuan, Zang Chuanli. A Study On Eye Movements In The Design Of Print Perfume Advertising Layout[J]. Studies of Psychology and Behavior,2006(03):172-176.

6. Ren Guiqin,He Liangqing,Zhou Yonglei.Eye Movement Research On Cognitive Processing Of Shampoo Print Advertising[J]. Chinese Journal of Ergonomics,2015,21(01):1-6.

7. Bai Xuejun,Gong Zhun,Yang Haibo,Tian Jin.Eye Movement Evaluation Of The Influence Of Location And Content On Web Advertising Effects[J].Chinese Journal of Applied Psychology, 2008, 14(03): 208-212+219.

8. Zhu Guoqi,Sun Linyan,Cui Kai.Research On The Influencing Factors Of Print Advertising Effect Based On Eye Movement Behavior Analysis Method[J].Management Review,2012,24(09):119-129.

9. Li Baozhu, Wei Shaomu.The Influence Of The Form Of Public Notification On Product Feedback: Evidence Based On Eye Movement[J]. Acta Psychologica Sinica,2018,50(01):69-81.

10. Ding Jinhong, Wang Jun, Zhang Qin.A Study On The Differences Between Graphic And Text Processing In Print Advertisements[J]. Psychological 
Exploration,2004(04):30-34.

11. Li Baoku, Wang Qiaoli.A Study On The Cognitive Effects Of Metaphors And Direct Narrative Image Advertising Eye Movements: The Moderating Role
Of Thinking Modes[J]. Journal of Liaoning Technical University (Social Science Edition), 2019, 21(03): 161-169. 